\title{
The Evaluation of Knowledge Innovation Capability Based on ANP
}

\author{
Ailing Yan ${ }^{1, a^{*}}$, Hong Jiang ${ }^{2, b}$ \\ ${ }^{1}$ School of Business Administration, Zhejiang Gongshang University, Hangzhou, China \\ ${ }^{2}$ Institute of Policy and Management, Chinese Academy of Sciences, Beijing, China \\ a*alyan@foxmail.com, bJohncn@foxmail.com
}

Keywords: ANP, Knowledge innovation, Indicators system, KIC, Evaluation

Abstract. Along with quick development of global economy, knowledge innovation capability (KIC) is gradually becoming one of the most important motility of enterprise growth. Therefore, how to evaluate KIC is increasingly becoming a hot topic. In order to properly evaluate and improve KIC for enterprise or region, through introducing an analytical network process (ANP) model, this study reports an application of proposed methodology as a case study related to large and medium-sized industrial enterprises in China.

\section{Introduction}

Along with quick development of global economy, knowledge innovation has become an imperative competitive tool to achieve sustainable competitive advantages. It is widely held that developing an excellent knowledge innovation capability (KIC) is unavoidable in adapting to the highly dynamic competitive environment, making it an important area for research in academia (Shane \& Ulrich, 2004) ${ }^{[1]}$.

\section{KIC and the indicators for KIC evaluation}

KIC is a capability of enterprise own, that is , a capability that enterprises find knowledge, and then accumulate, assimilate, understand, grasp even exert it in practice, which is vital for enterprises to gain competitive advantages. How to evaluate the KIC of enterprise is, therefore, being attached more and more importance.

The review about the indicators for KIC evaluation. Adler and Shenbar(1990) defined KIC as the ability to develop and respond and identified its four dimensions based on the process of knowledge innovation ${ }^{[2]}$. Moore(2004) distinguished KIC into disruptive, applicative, product, process, marketing, structural, and business model capabilities as he connected these with the market development life cycle ${ }^{[3]}$. From these previous definitions and indicators, it can be observed that KIC have described the process of knowledge innovation and consider that the aim of KIC is to apply a set of appropriate process technologies to producing new products that meet market needs.

The principle to establish evaluation indicator system. On the basis of those existing study, this study follows the process perspective and seeks to establish our own indicator system for KIC evaluation and firstly confirms the principle to establish evaluation indicator system. Some principles, which contain principle considering both qualitative and quantitative indicators, scientific principle, feasibility principle and system principle ${ }^{[4]}$, should be observed so as to reflect KIC objectively and exactly when designing the evaluation indicator system. Additionally, it is necessary to control reasonably the scale of indicator system.

The evaluation indicators system of KIC. The indicators system of this study has six main indicators which contains fourteen sub-indicators. The indicators and their definitions are shown in Table 1 . Therefore, according to the principles above and existing studies, the evaluation indicator system of KIC is confirmed.

\section{ANP model for KIC evaluation}

Introduction to ANP. ANP, which was developed by Saaty in 1996, developed from Analytic Hierarchy Process (AHP). Saaty (1996) has suggested the use of AHP to solve the problem of 
independence among alternatives or criteria, and the use of ANP to solve the problem of dependence among alternatives or criteria. ${ }^{[5]}$ In order to detect the interaction and dependency, decision-maker can use input-output analysis which was proposed by Leontief in analyzing the US economy. Input-output analysis explained the interconnection among sectors of complex economic systems, which may be national, regional, or enterprise type (Li and Liu, 2008) ${ }^{[6]}$.

Supermatrix in ANP. ANP assumes that there was a system with N clusters or components, where the elements in each component interact or have an impact on the other elements. A priority vector derived from paired comparisons in a usual way represents the impacts of a given set of elements in a component on another element in the system. A supermatrix is composed of the priority vectors derived from pairwise comparison matrices. Vectors that form this matrix are ratio scale priority vectors derived by pair-wise comparison matrices. These comparison matrices demonstrate the judgment of decision-maker about the priority of elements. It is not necessary that every element of a cluster has an influence on an element in another cluster. For deriving judgment of the decision-maker and establishing the comparison matrices, the scale that was suggested by Saaty for ANP can be used(Lin et al., 2008) ${ }^{[7]}$.

Group Decision-Making in ANP. In ANP a final comparison matrix indicating the judgments of decision-makers on the pair-wise comparisons should be calculated in group decision-making. Then, the ratio scale priority vectors of the final comparison matrix should be figured out. Now these caculated vectors should be put in their appropriate positions in the supermatrix. The elements of the final comparison matrix are calculated through the geometric mean of elements in comparison matrix of each decision-maker. The study of Azar and Rajabzade(2002) ${ }^{[8]}$ has provided specific calculation methods.

The KIC evaluation system based on ANP. Knowledge innovation is a complicated system engineering. To make the system reflect the connotation and law of knowledge innovation, it is necessary to set up a representative, integrity and systemic indicators system. In some previous studies, it is the default that the several indicators of KIC are independent and adopt AHP hierarchical structure. But it doesn't meet the actual situation, for example, knowing from experience: capability of distinguishing knowledge will affect the input of knowledge foundation. Given the shortcomings of AHP structure, this study used ANP method to construct the network structure of the elements among six main indicators in Table 1.

\section{Case Study}

In this study, the statistical date of large and medium-sized industrial enterprises is treated as input, according to "2014 China statistical yearbook on science and technology", evaluating and ranking the KIC of enterprises in every regions of China Mainland, based on the ANP model. The evaluation process of KIC based on ANP is described in the below stepwise manner:

Step 1. Determining the important criteria of KIC evaluation. In this stage, interviews with 20 experts were conducted to determine the criteria for KIC evaluation. In these interviews, Delphi method was used. At last, fourteen criteria were recognized. After making sure that all 20 experts have a common understanding of the criteria regarding the information obtained from the interviews, the criteria were classified into six categories (clusters). The criteria and their definitions are shown in Table 1.

Step 2. Designing the network of decision. In this stage, an input-output analysis was made. To do this, interviews with 20 experts were conducted. Then, an input-output matrix (the entries or elements of which are zero and one) was designed. Number one symbolize the existence of corresponding row element impact on the corresponding column element and zero showed that there is no impact. With the help of input-output matrix, the network was designed as shown in Fig. 1. Nodes of the network represent components of the evaluation system, a arc is used to show the interdependency relationships that occur within them. The directions of the arcs signify dependence, arcs emanate from an attribute to other attributes that may influence it. In order to build the decision problem, all interactions among the elements should be considered. 
Table 1 Criteria and sub criteria for the evaluation of KIC

\begin{tabular}{|c|c|c|}
\hline Criteria & Subcriteria & Definition \\
\hline \multirow[t]{2}{*}{$\begin{array}{l}\mathrm{X}_{1}: \text { Knowledge } \\
\text { foundation }\end{array}$} & $\begin{array}{l}\mathrm{X}_{11} \text { : Percentage of R\&D personal in a } \\
\text { firm's total employment }\end{array}$ & $\mathrm{R} \& \mathrm{D}$ personal/total employment \\
\hline & $\begin{array}{l}\mathrm{X}_{12}: \text { Number of Enterprises Having R\&D } \\
\text { Institutions }\end{array}$ & $\begin{array}{l}\text { Number of Enterprises Having R\&D } \\
\text { Institutions /number of firms }\end{array}$ \\
\hline \multirow{3}{*}{$\begin{array}{l}\mathrm{X}_{2} \text { : Capability } \\
\text { of distinguishing } \\
\text { knowledge }\end{array}$} & $\begin{array}{l}\mathrm{X}_{21}: \text { Expenditures for indraught of } \\
\text { technology }\end{array}$ & $\begin{array}{l}\text { Total expenditure for indraught of } \\
\text { technology/number of firms }\end{array}$ \\
\hline & $\begin{array}{l}\mathrm{X}_{22} \text { : Expenditure for Assimilation of } \\
\text { Technology }\end{array}$ & $\begin{array}{l}\text { Total Expenditure for Assimilation of } \\
\text { Technology/number of firms }\end{array}$ \\
\hline & $\begin{array}{l}\mathrm{X}_{23}: \text { Full-time Equivalent of R\&D } \\
\text { Personnel }\end{array}$ & $\begin{array}{l}\text { Total time spent in R\&D activities/norm of } \\
\text { working hour one R\&D person per year }\end{array}$ \\
\hline \multirow{4}{*}{$\begin{array}{l}\mathrm{X}_{3} \text { : Capability } \\
\text { of knowledge } \\
\text { creation }\end{array}$} & $\mathrm{X}_{31}$ : External Expenditure on R\&D & $\begin{array}{l}\text { Total External Expenditure on R\&D/number } \\
\text { of firms }\end{array}$ \\
\hline & $\mathrm{X}_{32}$ : Intramural Expenditure on R\&D & $\begin{array}{l}\text { Total Intramural Expenditure on } \\
\text { R\&D/number of firms }\end{array}$ \\
\hline & $\begin{array}{l}\mathrm{X}_{33} \text { : Average Expenditure for Technical } \\
\text { Renovation }\end{array}$ & $\begin{array}{l}\text { Expenditure for Technical } \\
\text { Renovation/number of firms }\end{array}$ \\
\hline & $\begin{array}{l}\mathrm{X}_{34}: \text { Expenditure on New Products } \\
\text { Development }\end{array}$ & $\begin{array}{l}\text { Total Expenditure on New Products } \\
\text { Development /number of firms }\end{array}$ \\
\hline \multirow{3}{*}{$\begin{array}{l}\mathrm{X}_{4} \text { : Capability of } \\
\text { knowledge } \\
\text { output }\end{array}$} & $\begin{array}{l}\mathrm{X}_{41}: \text { Average Number of Patents in } \\
\text { Force }\end{array}$ & Total Patents in Force/number of firms \\
\hline & $\begin{array}{l}\mathrm{X}_{42} \text { : Yield ratio of new product } \\
\text { development }\end{array}$ & $\begin{array}{l}\text { Output Value of New Products/expenditures } \\
\text { on R\&D }\end{array}$ \\
\hline & $\mathrm{X}_{43}$ : Content of new technology & $\begin{array}{l}\text { Industrial output value of new product/gross } \\
\text { industrial output value }\end{array}$ \\
\hline $\begin{array}{l}\mathrm{X}_{5} \text { : Capability of } \\
\text { marketing } \\
\text { knowledge }\end{array}$ & $\begin{array}{l}\mathrm{X}_{51}: \text { Percentage of new product sales to } \\
\text { sales revenue }\end{array}$ & $\begin{array}{l}\text { Sales of new product/ Revenue from Principal } \\
\text { Business }\end{array}$ \\
\hline $\mathrm{X}_{6}:$ Profitability & $\mathrm{X}_{61}:$ Average Profits & Total Profits /number of firms \\
\hline
\end{tabular}

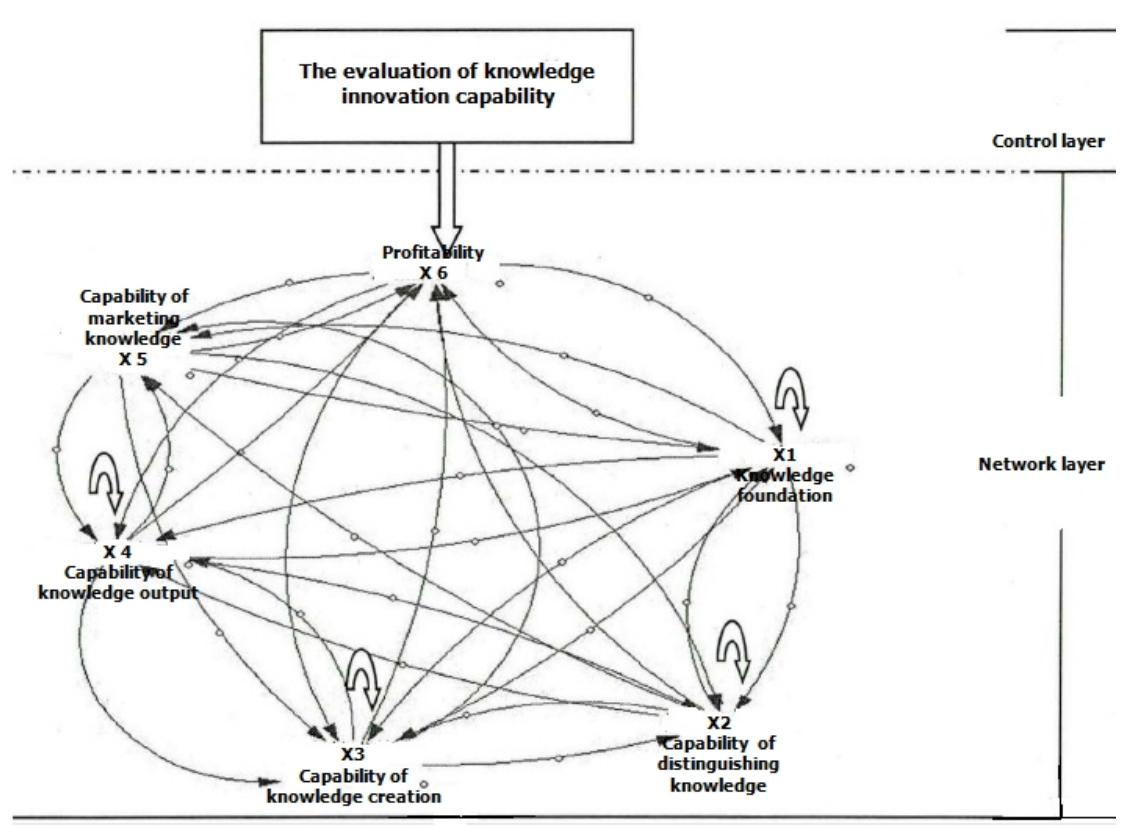

Figure 1. the network architecture of KIC evaluation system

Step 3. Calculating the weights of the criteria. Firstly, deriving 20 experts' judgments from comparison matrices and establishing the supermatrix. Based on the input-output analysis and decision network, a questionnaire was designed to derive pair-wise comparison judgments. The comparison matrices among the elements were integrated after 20 experts answered the questionnaires. According to the two criteria of constructing ANP comparison matrix ${ }^{[9]}, 20$ experts have been consulted. This led to the final comparison matrices to achieve the ratio scale vectors. Secondly, calculating the weighted supermatrix (stochastic supermatrix). In the last part of the 
questionnaires, some questions were asked to find out the impact of the clusters on each other so as to obtain final comparison matrices and the ratio scale vectors. Then to obtain the weighted supermatrix or stochastic supermatrix, the final comparison matrices foregoing are multiplied by the elements of their corresponding blocks in the supermatrix. The third, calculating the weights of the criteria. In this stage, the powers of weighted supermatrix are calculated to obtain the limited supermatrix. After 14th iteration (14th power), the limited supermatrix is obtained. Each column of the limited supermatrix determine the final ratio scale priority of elements in network. The final weight of each element and cluster is shown in Table 2. In this table, the cluster's ratio scale priority is equal to sum of its elements' ratio scale priority. The ratio scale priorities of the elements within their clusters (last column) are calculated by normalizing their ratio scale priority in the related cluster.

Table 2 The relative importance of clusters and elements

\begin{tabular}{|c|c|c|c|c|}
\hline Clusters & Elements & $\begin{array}{l}\text { (1)Ratio sca } \\
\text { the network }\end{array}$ & $\begin{array}{l}\text { (2)Ratio scale } \\
\text { priority of clusters }\end{array}$ & $\begin{array}{l}(3)=(1) /(2) \text { Ratio scale priority } \\
\text { of of elements in their cluster }\end{array}$ \\
\hline \multirow{2}{*}{$\overline{X_{1}}$} & $\mathrm{X}_{11}$ & 0.048 & \multirow[t]{2}{*}{0.065} & 0.738 \\
\hline & $\mathrm{X}_{12}$ & 0.017 & & 0.262 \\
\hline \multirow[t]{3}{*}{$\mathrm{X}_{2}$} & $\mathrm{X}_{21}$ & 0.080 & \multirow[t]{3}{*}{0.137} & 0.584 \\
\hline & $\mathrm{X}_{22}$ & 0.026 & & 0.190 \\
\hline & $X_{23}$ & 0.031 & & 0.226 \\
\hline \multirow[t]{4}{*}{$\mathrm{X}_{3}$} & $X_{31}$ & 0.063 & \multirow[t]{4}{*}{0.244} & 0.258 \\
\hline & $X_{32}$ & 0.070 & & 0.287 \\
\hline & $X_{33}$ & 0.055 & & 0.225 \\
\hline & $X_{34}$ & 0.056 & & 0.230 \\
\hline \multirow[t]{3}{*}{$\mathrm{X}_{4}$} & $X_{41}$ & 0.012 & \multirow[t]{3}{*}{0.364} & 0.033 \\
\hline & $\mathrm{X}_{42}$ & 0.226 & & 0.621 \\
\hline & $\mathrm{X}_{43}$ & 0.126 & & 0.346 \\
\hline $\mathrm{X}_{5}$ & $\mathrm{X}_{51}$ & 0.165 & 0.165 & 1.000 \\
\hline $\mathrm{X}_{6}$ & $X_{61}$ & 0.025 & 0.025 & 1.000 \\
\hline
\end{tabular}

Table 3 The Rank of KIC

\begin{tabular}{|l|l|l|r|l|l|l|l|l|}
\hline Region & Result & Rank & Region & Result & Rank & Region & Result & Rank \\
\hline Beijing & 72.243 & 1 & Henan & 21.659 & 28 & Zhejiang & 44.771 & 6 \\
\hline Tianjin & 54.324 & 4 & Hubei & 33.443 & 16 & Anhui & 37.132 & 12 \\
\hline Hebei & 22.827 & 27 & Hunan & 39.374 & 10 & Fujian & 32.565 & 17 \\
\hline Shanxi & 29.158 & 20 & Guangdong & 42.612 & 7 & Jiangxi & 20.633 & 29 \\
\hline Inner Mongolia & 28.728 & 21 & Guangxi & 31.862 & 18 & Shandong & 33.590 & 14 \\
\hline Liaoning & 23.633 & 25 & Hainan & 33.613 & 13 & Shaanxi & 33.519 & 15 \\
\hline Jilin & 46.99 & 5 & Chongqing & 61.615 & 3 & Gansu & 41.256 & 8 \\
\hline Heilongjiang & 27.691 & 22 & Sichuan & 27.039 & 23 & Qinghai & 17.353 & 30 \\
\hline Shanghai & 62.328 & 2 & Guizhou & 38.235 & 11 & Ningxia & 30.539 & 19 \\
\hline Jiangsu & 40.635 & 9 & Yunnan & 24.069 & 24 & Xinjiang & 23.252 & 26 \\
\hline Xizang & 11.644 & 31 & & & & & & \\
\hline
\end{tabular}

Step 4. Results of the rank of KIC. Since the data of different indicators are not the same standard for comparison, the non-dimensional method is used to process the sample data before evaluation. The formula as follow: $\ell_{i j}=\frac{100 x_{i j}}{\max _{1 \leq i \leq m}\left\{x_{i j}\right\}}$, which $m=31$, where, $m$ represents the number of samples. The linear evaluation model $y_{i}=\sum_{j=1}^{n} w_{j} \ell_{i j}$ is adopted, which $y_{i}$ represents the comprehensive evaluation value of the i-th object being evaluated, $\ell_{i j}$ represents the standardized data of evaluated objects, $w_{j}$ represents the weight coefficient of evaluated objects, and $\mathrm{n}$ refers to the number of indicators, where $n=14$. Using KIC indicators and weights in Table 2, the results are shown in Table 3. 


\section{Conclusions}

From the results of the rank of KIC above, the medium-sized industrial enterprises in Beijing have a relatively high KIC in 2013, while the medium-sized industrial enterprises in the other most regions have a relatively low KIC. It is obviously that the result is largely related to innovation inputs and the structure of local intellectuals. In order to enhance regional KIC, several measures are suggested as below:

Firstly, it is necessary to increase numbers of R\&D personal. Number of R\&D personal is one of the most important symbol of the level of KIC. The ratio of R\&D personal should be enhanced.

Secondly, it is necessary to actively introduce foreign advance techniques. It is a necessary condition for enforcing KIC.

The third, it is necessary to enforce regional specialists training. Enterprises should actively encourage individual inventions and patent application. At the same time, Enterprises should also try to train scientific, technological and management intellectuals.

The evaluation of KIC is a continuous task. The evaluation model presented in this study is an attempt to aid decision makers in the complex task of prioritizing their options. This study establishes indicators for KIC evaluation, and these indicators should appropriately be adjusted within the economy development. Further studies are therefore needed to investigate these issues.

\section{References}

[1] Shane, S. A. and Ulrich, K. T. 'Technological Innovation, Product Development, and Entrepreneurship in Management Science', Management Science, 2004, Vol. 50, pp. 133-144.

[2] Adler, P.S. and Shenbar, A. 'Adapting your technological base: The organizational challenge', Sloan Management Review, 1990, Vol. 25, pp. 25-37.

[3] Moore, G.A. 'Darwin and the Demon: Innovation within Established Enterprises', Harvard Business Review, 2004, Vol. 82, pp. 86-92.

[4] TONG Zehua1, and HAN Chun-hua Evaluation of Enterprise Knowledge Innovation Capability Based on BP Neural Network, Proceedings of 2009 International Conference on Management Science and Engineering, ISBN: 978-0-9806057-9-2. 2009.

[5] Saaty, T.L. Decision Making with Feedback: The Analytical Network Process. RWS Publications, Pittsburg, 1996,pp:15 20.

[6] Li, Q.X., Liu, S.F. The foundation of the grey matrix and the grey input-output analysis. Applied Mathematical Modeling, 2008,32(3), 267-29.

[7] Lin, R., Lin, J.J., Shu, C.J., Diodes, T., Chao, H., Peter, J.C. Note on group consistency in analytic hierarchy process. European Journal of Operational Research, 2008,190(3), 627-678.

[8] Azar, A., Rajabzadeh, A. Applied decision-making (M.A.D.M approach). Negah Danesh, Tehran.2002.

[9] Saaty T L. Fundamentals of the analytic network process-dependence and feedback in decisionmaking with a single network[J]. Journal of Systems science and Systems engineering, 2004, 6. 